\title{
Video Article \\ Transient Treatment of Human Pluripotent Stem Cells with DMSO to Promote Differentiation
}

\author{
Danielle Sambo ${ }^{1}$, Jingling Li ${ }^{1}$, Thomas Brickler ${ }^{1}$, Sundari Chetty ${ }^{1,2}$ \\ ${ }^{1}$ Department of Psychiatry and Behavioral Sciences, Stanford University School of Medicine \\ ${ }^{2}$ Institute for Stem Cell Biology and Regenerative Medicine, Stanford University School of Medicine
}

Correspondence to: Sundari Chetty at chettys@stanford.edu

URL: https://www.jove.com/video/59833

DOI: doi: $10.3791 / 59833$

Keywords: Developmental Biology, Issue 149, human pluripotent stem cells, differentiation, DMSO, retinoblastoma protein, cell cycle, cell fate Date Published: 7/17/2019

Citation: Sambo, D., Li, J., Brickler, T., Chetty, S. Transient Treatment of Human Pluripotent Stem Cells with DMSO to Promote Differentiation. J. Vis. Exp. (149), e59833, doi:10.3791/59833 (2019).

\section{Abstract}

Despite the growing use of pluripotent stem cells (PSCs), challenges in efficiently differentiating embryonic and induced pluripotent stem cells (ESCs and iPSCs) across various lineages remain. Numerous differentiation protocols have been developed, yet variability across cell lines and low rates of differentiation impart challenges in successfully implementing these protocols. Described here is an easy and inexpensive means to enhance the differentiation capacity of PSCs. It has been previously shown that treatment of stem cells with a low concentration of dimethyl sulfoxide (DMSO) significantly increases the propensity of a variety of PSCs to differentiate to different cell types following directed differentiation. This technique has now been shown to be effective across different species (e.g., mouse, primate, and human) into multiple lineages, ranging from neurons and cortical spheroids to smooth muscle cells and hepatocytes. The DMSO pretreatment improves PSC differentiation by regulating the cell cycle and priming stem cells to be more responsive to differentiation signals. Provided here is the detailed methodology for using this simple tool as a reproducible and widely applicable means to more efficiently differentiate PSCs to any lineage of choice.

\section{Video Link}

The video component of this article can be found at https://www.jove.com/video/59833/

Introduction

The use of pluripotent stem cells has led to numerous advancements in biomedical research, including the fields of regenerative medicine and stem-cell based therapies, disease modeling, and drug screening. It has also led to the overall prospect of more translatable research and personalized medicine. The advent of induced pluripotent stem cell (iPSC) technology over 20 years ago has allowed researchers to develop pluripotent stem cells from somatic tissues and differentiate them into functional cell types to study a variety of pathologies, including cardiovascular, neurological, and immunological diseases. Although significant strides have been made in stem cell differentiation technology, challenges in effectively differentiating human embryonic stem cells (hESCs) and iPSCs still persist, limiting the widespread use of stem cell technology across different research programs. Inherent variability across different cell lines and clones continues to pose obstacles for differentiating stem cell lines to desired linages ${ }^{1}$. Furthermore, deriving mature, terminally differentiated functional cells from hPSCs remains a tedious and inefficient process across many lineages. In fact, cells differentiated from hPSCs often fail to terminally differentiate into functional cells $^{2}$. In further moving stem cell-based therapies to use in patients, there is a need to improve and ensure the efficacy of cells that are generated from hPSCs.

Our lab has established a quick, inexpensive tool to significantly enhance the efficiency of differentiating both iPSCs and ESCs into mature cell types. We found that pretreatment of hiPSCs and hESCs with the commonly used reagent dimethyl sulfoxide (DMSO) for $24 \mathrm{~h}$ to $48 \mathrm{~h}$ prior to directed differentiation results in a marked improvement in stem cell differentiation capacity. Treatment with DMSO increases the proportion of hiPSCs and hESCs in the early G1 phase of the cell cycle and activates the retinoblastoma protein $(\mathrm{Rb})^{3}$, a critical regulator of cell proliferation, survival, and differentiation ${ }^{4}$. In more recent work, it has been found that $\mathrm{Rb}$ and its family members are required for the pro-differentiation effects of DMSO, such that transient inactivation of Rb suppresses the effects of DMSO, while constitutive activation of Rb in a transient manner enhances DMSO's effects ${ }^{5}$. Analogous to the cell cycle during embryonic development, the cell cycle of ESCs and iPSCs is characterized by an abbreviated $\mathrm{G} 1$ phase that promotes self-renewal ${ }^{6,7,8}$. This abbreviated $\mathrm{G} 1$ phase allows for more unrestricted proliferation but limits the potential for differentiation ${ }^{4,9}$. By promoting growth arrest in G1 and activating checkpoint controls in the cell cycle of hESCs and iPSCs, the DMSO treatment primes cells for cell fate changes following directed differentiation.

To date, DMSO pretreatment has been shown to improve the differentiation capacity to all three germ layers in over 30 control and diseasespecific human ESC and iPSC cell lines ${ }^{3,5}$ as well as the differentiation of stem cells and other cell lines to a variety of other mature cell types in subsequent studies ${ }^{10,11,12,13,14,15,16,17,18,19,20,21,22,23,24,25,26,27,28}$ (Table 1). Furthermore, DMSO treatment has been shown to be effective in enhancing differentiation of non-human primary cells ${ }^{21,23}$ (e.g., mouse, primate, rabbit), suggesting shared mechanisms across species. Lastly, DMSO pretreatment has also been extended to gene editing technology, with one particular study showing that $24 \mathrm{~h}$ DMSO pretreatment of 
hESCs/iPSCs significantly increased the ability of Clustered Regularly Interspaced Short Palindromic Repeats (CRISPR)/CRISPR-associated protein-9 (Cas9)-mediated editing efficiency of non-coding DNA without incorporating unintended mutations ${ }^{29}$. Provided here is a detailed methodology of the DMSO pretreatment of hESCs and iPSCs for applications in stem cell biology and directed differentiation.

\section{Protocol}

\section{Stem Cell Maintenance}

NOTE: The cell maintenance protocol described below applies to pluipotent stem cells (PSCs) maintained in an adherent monolayer. Media, other reagents, and cell culture plates used prior to DMSO treatment can be adjusted as needed. For all the following protocols in this manuscript, cells should be handled under a biological safety cabinet.

1. Coat sterile, 6 well, tissue culture-treated plates with a pluripotent stem cell-qualified matrix or substrate prepared per the manufacturer's instructions and incubate for at least $1 \mathrm{~h}$ in a $\mathrm{CO}_{2}$ incubator $\left(5 \% \mathrm{CO}_{2}\right.$, humid atmosphere). Coated plates can be film wrapped and stored at 4 ${ }^{\circ} \mathrm{C}$ for up to one week.

2. Thaw the cryopreserved PSCs in a $37^{\circ} \mathrm{C}$ water bath. Sterilize vial with ethanol prior to introduction to the biological safety cabinet, then immediately transfer the cells by pipetting to a sterile conical tube containing 5-10 volumes of prewarmed stem cell media.

3. Centrifuge the cells at $300 \times g$ for $5 \mathrm{~min}$ at room temperature (RT).

4. Aspirate the media and gently resuspend the cell pellet in $1 \mathrm{~mL}$ of stem cell media supplemented with a $10 \mu \mathrm{M}$ ROCK inhibitor, such as Y-27632.

5. Aspirate the culture matrix from the plate and seed the cells at the desired density, typically $0.5-1 \times 10^{6}$ cells per well in at least $2 \mathrm{~mL}$ of stem cell media per well.

NOTE: The plating density can vary across different cell lines, and clones and should be optimized accordingly.

6. Maintain the cells by replacing with prewarmed stem cell media daily. Split the cells at roughly $70 \%-80 \%$ confluency or when the cell colonies begin to make contact.

7. For splitting cells, aspirate the media and wash the cells once with sterile PBS. Incubate the cells with $1 \mathrm{~mL}$ of a dissociation enzyme solution per well for $5-10$ minutes at $37^{\circ} \mathrm{C}$

8. Wash and resuspend the cells with prewarmed stem cell media and transfer to a sterile conical tube with 5-10 volumes of stem cell media. Follow steps 1.3-1.7 to plate the cells.

\section{DMSO Pretreatment}

NOTE: When plating the cells for DMSO pretreatment prior to differentiation, the starting plating cell density should be optimized with consideration of the typical growth rate of the stem cell line as well as the differentiation protocol being used. Validate pluripotency using conventional markers, as necessary. Cells should be passaged at least $1 \mathrm{x}-2 \mathrm{x}$ after initial thawing prior to differentiation.

\section{2D culture differentiation}

1. When the cells reach an appropriate confluency, prepare coated plates, dissociate the cells, and prepare a single-cell suspension as described above.

2. Count the live cells using a hemocytometer or automatic cell counter including trypan blue or another viability marker.

3. Plate the cells onto a coated 6 well plate at $0.5-1 \times 10^{6}$ cells per well in stem cell media with the $10 \mu \mathrm{M}$ ROCK inhibitor.

NOTE: For the cell lines tested in our laboratory, these densities typically resulted in $80 \%-90 \%$ confluent cells within the $24 \mathrm{~h}$ DMSO pretreatment.

4. Allow cells to incubate for $24 \mathrm{~h}$ at $37^{\circ} \mathrm{C}$ in a $\mathrm{CO}_{2}$ incubator $\left(5 \% \mathrm{CO}_{2}\right.$, humid atmosphere).

5. Prepare $1 \%-2 \%$ DMSO in prewarmed stem cell media (e.g., $100 \mu \mathrm{L}$ of DMSO in $10 \mathrm{~mL}$ of media $=1 \%$ DMSO solution, or $200 \mu \mathrm{L}$ DMSO in $10 \mathrm{~mL}$ of media $=2 \%$ DMSO solution).

6. After $24 \mathrm{~h}$ incubation, aspirate the media from cells and replace it with DMSO solution.

7. Allow the cells to incubate for $24 \mathrm{~h}$ to $48 \mathrm{~h}$ at $37^{\circ} \mathrm{C}$ in a $\mathrm{CO}_{2}$ incubator $\left(5 \% \mathrm{CO}_{2}\right.$, humid atmosphere) prior to differentiation. NOTE: Typically, a $24 \mathrm{~h}$ DMSO treatment is sufficient across a majority of human ESC and iPSC lines. Cell lines with very slow growth rates (long doubling times) can benefit from the $48 \mathrm{~h}$ incubation with DMSO. For a $48 \mathrm{~h}$ incubation with DMSO, media can be replaced with fresh stem cell media with 1\%-2\% DMSO after the first $24 \mathrm{~h}$ of treatment.

\section{3D culture differentiation:}

1. When the cells reach an appropriate confluency, dissociate and collect the cells in a cell suspension as described above.

2. Count the live cells using a hemocytometer or automatic cell counter including a viability marker.

3. Plate the cells in an uncoated, low-attachment 6 well plate at $0.5-1 \times 10^{6}$ cells per well in stem cell media with $10 \mu \mathrm{M}$ ROCK inhibitor. NOTE: For the cell lines tested in our laboratory, these densities typically resulted in 3D hPSC sphere formation within $24 \mathrm{~h}$ of setting cells.

4. Allow cells to incubate for $24 \mathrm{~h}$ at $37{ }^{\circ} \mathrm{C}$ in a $\mathrm{CO}_{2}$ incubator $\left(5 \% \mathrm{CO}_{2}\right.$, humid atmosphere).

5. Prepare $1 \%-2 \%$ DMSO in prewarmed stem cell media (e.g., $100 \mu \mathrm{L}$ of DMSO in $10 \mathrm{~mL}$ of media $=1 \%$ DMSO solution, or $200 \mu \mathrm{L}$ of DMSO in $10 \mathrm{~mL}$ of media $=2 \%$ DMSO solution).

6. Replace the media following standard procedures (e.g., tilt the plate at a $30^{\circ}-45^{\circ}$ angle to allow cell spheres to settle at the bottom of the well; transfer cells to a sterile conical tube and allow cell spheres to settle at the bottom of the tube; or gently collect cells in suspension using a 5 or $10 \mathrm{~mL}$ pipette into a sterile conical tube and centrifuge cells at $300 \times g$ for 5 min at RT).

7. Aspirate the media from cells and replace it with DMSO solution, pipetting gently.

8. Allow cells to incubate for $24 \mathrm{~h}$ to $48 \mathrm{~h}$ at $37^{\circ} \mathrm{C}$ in a $\mathrm{CO}_{2}$ incubator $\left(5 \% \mathrm{CO}_{2}\right.$, humid atmosphere $)$ prior to differentiation. 
NOTE: Typically, a $24 \mathrm{~h}$ DMSO treatment is sufficient across a majority of human ESC and iPSC lines. Cell lines with very slow growth rates (long doubling times) can benefit from the $48 \mathrm{~h}$ incubation with DMSO. For a $48 \mathrm{~h}$ incubation with DMSO, media can be replaced with fresh stem cell media with $1 \%-2 \%$ DMSO after the first $24 \mathrm{~h}$ of treatment.

\section{Differentiation to Primary Germ Layers}

NOTE: The following describes methods previously shown to be effective in our laboratory for PSCs grown in a monolayer on 6 well plates. Any differentiation protocol of choice should be used after the DMSO treatment to promote differentiation into desired lineages. Remove DMSO solution after a $24-48 \mathrm{~h}$ treatment and proceed with differentiation following standard protocols.

1. Endoderm differentiation (adapted from Kroon et al. ${ }^{30}$ )

1. Pretreat cells with DMSO as described above for 2D cultures.

2. Prepare Wnt3a and Activin A stock solutions.

3. Prepare Day 1 endodermal differentiation media by adding Wnt3a to a final concentration of $20 \mathrm{ng} / \mathrm{mL}$ and Activin A to a final concentration of $100 \mathrm{ng} / \mathrm{mL}$ to the appropriate volume of prewarmed RPMI media.

4. After DMSO pretreatment, aspirate media from the cells and replace it with Day 1 media (e.g., $2 \mathrm{~mL}$ per well of a 6 well plate).

5. Allow cells to incubate for $24 \mathrm{~h}$ at $37^{\circ} \mathrm{C}$ in a $\mathrm{CO}_{2}$ incubator $\left(5 \% \mathrm{CO}_{2}\right.$, humid atmosphere).

6. Prepare Days 2 and 3 endodermal differentiation media by adding Activin A to a final concentration of $100 \mathrm{ng} / \mathrm{mL}$ to the appropriate volume of prewarmed RPMI media.

7. Aspirate media from the cells and replace it with Day 2 media (e.g., $2 \mathrm{~mL}$ per well of a 6 well plate).

8. Allow the cells to incubate for $24 \mathrm{~h}$ at $37^{\circ} \mathrm{C}$ in a $\mathrm{CO}_{2}$ incubator $\left(5 \% \mathrm{CO}_{2}\right.$, humid atmosphere).

9. Aspirate media from the cells and replace with Day 3 media (e.g., $2 \mathrm{~mL}$ per well of a 6 well plate).

2. Mesoderm differentiation (adapted from Zhang et al. ${ }^{31}$ )

1. Pretreat the cells with DMSO as described above for $2 \mathrm{D}$ cultures.

2. Prepare Wnt3a and Activin A stock solutions.

3. Prepare mesodermal differentiation media by adding Wnt3a to a final concentration of $20 \mathrm{ng} / \mathrm{mL}$ and Activin A to a final concentration of $100 \mathrm{ng} / \mathrm{mL}$ to the appropriate volume of prewarmed advanced RPMI media.

4. After DMSO pretreatment, aspirate media from cells and replace with differentiation media (e.g., $2 \mathrm{~mL}$ per well of a 6 well plate).

5. Allow cells to incubate for $24 \mathrm{~h}$ at $37^{\circ} \mathrm{C}$ in a $\mathrm{CO}_{2}$ incubator $\left(5 \% \mathrm{CO}_{2}\right.$, humid atmosphere).

3. Ectoderm differentiation (adapted from Chambers et al. ${ }^{32}$ )

1. Pretreat the cells with DMSO as described above for $2 \mathrm{D}$ cultures.

2. Prepare Noggin and SB431542 stock solutions.

3. Prepare ectodermal differentiation base media by dissolving knockout serum replacement (KOSR) to a final concentration of $10 \%$ in knockout DMEM.

NOTE: Prepare enough base media for 3-4 days of media change.

4. Prepare ectodermal differentiation media by adding Noggin to a final concentration of $500 \mathrm{ng} / \mathrm{mL}$ and SB431542 to a final concentration of $10 \mu \mathrm{M}$ to the appropriate volume of prewarmed KOSR/knockout DMEM.

5. After DMSO pretreatment, aspirate media from cells and replace with differentiation media (e.g., $2 \mathrm{~mL}$ per well of a 6 well plate).

6. Allow cells to incubate for $3-4$ days at $37^{\circ} \mathrm{C}$ in a $\mathrm{CO}_{2}$ incubator $\left(5 \% \mathrm{CO}_{2}\right.$, humid atmosphere), replacing media daily with freshly added differentiation factors.

\section{Differentiation to Progenitor Cell Types}

The following describes methods previously shown to be effective in our laboratory for PSCs grown in a 2D or 3D cultures. Any differentiation protocol of choice should be used after the DMSO treatment to promote differentiation into desired lineages. Remove DMSO solution after a 24-48 $\mathrm{h}$ treatment and proceed with differentiation following standard protocols.

1. Neural progenitor cell differentiation (adapted from Tchieu et al. ${ }^{33}$ )

1. Prepare 6 well plates by coating with a pluripotent stem cell-qualified reduced growth factor matrix or substrate, per the manufacturer's instructions, for at least $1 \mathrm{~h}$ in a $\mathrm{CO}_{2}$ incubator $\left(5 \% \mathrm{CO}_{2}\right.$, humid atmosphere). Coated plates can be film wrapped and stored at $4{ }^{\circ} \mathrm{C}$ for up to 1 week.

2. Plate PSCs as described above at density of $0.5-1 \times 10^{6}$ cells per well in stem cell media containing a ROCK inhibitor.

3. Pretreat cells with DMSO as described above for $2 \mathrm{D}$ cultures.

4. Prepare small chemical inhibitors LDN193189, SB431542, and XAV939 stock solutions.

5. Prepare Days 1-3 neuroectoderm differentiation media by supplementing Essential 6 Media with $500 \mathrm{nM}$ LDN193189, $10 \mu \mathrm{M}$ SB431542, and $2 \mu \mathrm{M}$ XAV939.

6. After DMSO pretreatment, aspirate the media and replace with Days 1-3 neuroectoderm media (e.g., $2 \mathrm{~mL}$ per well of a 6 well plate). Change media daily.

7. Prepare Days 4-12 neuroectoderm differentiation media by supplementing Essential 6 Media with $500 \mathrm{nM}$ LDN193189 and $10 \mu \mathrm{M}$ SB431542.

8. On day 4 of differentiation, aspirate the media and replace with Days 4-12 neurodectoderm media. Change the media daily.

9. After 12 days of differentiation, differentiated cells should express appropriate markers of neural progenitor cells (NPCs). NPCs can be further maintained in neural media containing DMEM/F-12, 2\% B-27, $1 \% \mathrm{~N}-2$, and supplemented with $10 \mu \mathrm{g} / \mathrm{mL}$ basic fibroblast growth factor (bFGF). Passage the NPCs when confluent using a cell detachment solution, plating NPCs at $0.5-1 \times 10^{6}$ cells per well.

2. Oligodendrocyte progenitor cell differentiation (adapted from Douvaras and Fossati ${ }^{34}$ ) 
1. Plate the PSCs as described above at a density of $1 \times 10^{5}$ per well on coated 6 well plates in stem cell media containing a ROCK inhibitor.

2. Pretreat cells with DMSO as described above for 2D cultures.

3. Prepare SB431542, LDN193189, all-trans retinoic acid (RA), and smoothened agonist (SAG) stock solutions.

4. Prepare Days 0-8 differentiation media by supplementing DMEM/F-12 with $10 \mu \mathrm{M}$ SB431542, $250 \mathrm{nM}$ LDN193189, and $100 \mathrm{nM}$ RA.

5. After DMSO pretreatment, incubate cells with differentiation media for 8 days, changing media daily with freshly added differentiation factors (e.g., $2 \mathrm{~mL}$ per well of a 6 well plate).

6. On day 8, replace media with DMEM/F-12 containing 1x MEM non-essential amino acids (NEAA) solution, 1X L-glutamine, 2mercaptoethanol, penicillin/streptomycin, and $1 \times \mathrm{N}-2$ supplemented $100 \mathrm{nM}$ RA and $1 \mu \mathrm{M} \mathrm{SAG}$. Change the media daily.

7. After 12 days of differentiation, differentiated cells should express appropriate markers of oligodendrocyte progenitor cells (OPCs).

3. Endocrine progenitor cell differentiation (adapted from Pagliuca et al. ${ }^{35}$ )

1. Seed PSCs at $6 \times 10^{5}$ cells $/ \mathrm{mL}$ in stem cell media plus $10 \mu \mathrm{M}$ ROCK inhibitor in $500 \mathrm{~mL}$ spinner flasks placed on a 9-position stir plate set at rotation rate of $70 \mathrm{rpm}$ in a $37{ }^{\circ} \mathrm{C}$ incubator, $5 \% \mathrm{CO}_{2}$, and $100 \%$ humidity.

2. Allow clusters to settle at the bottom of the flask, aspirate the media, then pretreat with $1 \%-2 \%$ DMSO.

3. Prepare Activin A, Chir99021, KGF, Sant1, all-trans retinoic acid (RA), LDN193189, PdBU, XXI, Alk51, T3, and Betacelluin stock solutions.

4. Prepare differentiation base media based on formulation in Table 3.

5. After DMSO pretreatment, aspirate media and replace with $\mathrm{S} 1$ media supplemented with $100 \mathrm{ng} / \mathrm{mL}$ Activin A and $3 \mathrm{mM} \mathrm{Chir99021}$ (e.g., $500 \mathrm{~mL}$ per flask). Allow incubation for $24 \mathrm{~h}$.

6. On day 2, replace media with $\mathrm{S} 1$ media supplemented with $100 \mathrm{ng} / \mathrm{mL}$ Activin A. Allow incubation for 2 days.

7. On day 4, replace media with $\mathrm{S} 2$ media supplemented with $50 \mathrm{ng} / \mathrm{mL} \mathrm{KGF}$. Allow incubation for 3 days, changing media after the first 2 days (Day 6).

8. On day 7, replace media with $\mathrm{S} 3$ media supplemented with $50 \mathrm{ng} / \mathrm{mL}$ KGF, $0.25 \mathrm{mM}$ Sant1, $2 \mathrm{mM}$ RA, and $200 \mathrm{nM}$ LDN193189. Allow incubation for $24 \mathrm{~h}$.

9. On day 8, replace media with $\mathrm{S} 3$ media supplemented with $50 \mathrm{ng} / \mathrm{mL} \mathrm{KGF}, 0.25 \mathrm{mM}$ Sant1, $2 \mathrm{mM}$ RA, $200 \mathrm{nM}$ LDN193189, and 500 $\mathrm{nM}$ PdBU. Allow incubation for $24 \mathrm{~h}$.

10. On day 9 , replace media with $\mathrm{S} 3$ media supplemented with $50 \mathrm{ng} / \mathrm{mL}$ KGF, $0.25 \mathrm{mM}$ Sant1, and $100 \mathrm{nM}$ RA. Allow incubation for 5 days, changing media every 2 days (day 11 and 13 ).

11. On days 14 and 16 , replace media with S5 media supplemented with $0.25 \mathrm{mM}$ Sant1, $100 \mathrm{nM} \mathrm{RA}, 1 \mathrm{mM} \mathrm{XXI,} 10 \mathrm{mM} \mathrm{Alk5i} \mathrm{II,} 1 \mathrm{mM}$ T3, and $20 \mathrm{ng} / \mathrm{mL}$ betacellulin (4 days total incubation).

12. On days 18 and 20 , replace media with S5 media supplemented with $25 \mathrm{nM} \mathrm{RA}, 1 \mathrm{mM} \mathrm{XXI,} 10 \mathrm{mM} \mathrm{Alk5i} \mathrm{II,} 1 \mathrm{mM} \mathrm{T3}$, and $20 \mathrm{ng} / \mathrm{mL}$ betacellulin.

\section{Immunocytochemical Validation of Differentiation}

NOTE: The following methods describes a general immunocytochemical protocol that can be adjusted as needed. Primary antibodies are those that have been previously validated in our laboratory. Other techniques for validation of differentiation can also be used (e.g., flow cytometry, qPCR, RNA sequencing, western blotting, functional assays, etc.).

1. Immunolabeling cells

1. For 3D cultures in suspension, plate whole cell clusters or clusters dispersed into single-cell suspension onto coated plates for $18-24 \mathrm{~h}$ prior to fixation.

2. Aspirate media from adherent cells and wash briefly with PBS at RT on a shaker.

3. For cell fixation, aspirate PBS and incubate cells with $4 \%$ paraformaldehyde (PFA) in PBS for 20 min at RT on shaker. CAUTION: PFA stock should be prepared under a fume hood due to its toxicity. Do not inhale and wear proper personal protective equipment.

4. Remove PFA and discard in the proper chemical waste container.

5. Wash cells $3 x$ with PBS for at least 5 min per wash at RT on a shaker.

6. For cell permeabilization and blocking, incubate cells with $5 \%$ donkey serum prepared in $0.3 \%$ triton-x $100 / \mathrm{PBS}$ for $1 \mathrm{~h}$ at RT on a shaker.

7. Prepare primary antibody solution in the same solution used for permeabilization/blocking.

8. Incubate in primary antibody solution overnight at $4{ }^{\circ} \mathrm{C}$ on shaker.

9. After overnight incubation, wash cells $3 x$ with PBS for at least 5 min per wash at RT on a shaker.

10. Prepare secondary antibody solution in permeabilization/blocking solution.

11. Allow to incubate in secondary antibody solution for $1 \mathrm{~h}$ at RT on a shaker.

12. Aspirate secondary antibody solution and wash cells $3 x$ with PBS for at least 5 min per wash at RT on a shaker.

13. Incubate cells with DAPI or another preferred marker for appropriate incubation time, and rinse in PBS.

\section{Image quantification}

1. Acquire a minimum of three images per condition on a fluorescent microscope and/or with a high content screening platform.

2. Quantify the percent of positive cells for each marker by counting the total number of antibody stained cells and total cell numbers (based on DAPI/Hoechst nuclei staining) using unbiased imaging software (e.g., ImageJ) or an automated screening platform for analyses. 
Representative Results

\section{Morphology of DMSO treated iPSCs}

Human iPSCs derived from control subjects were cultured either in an adherent 2D monolayer or in 3D cell spheres in suspension. Approximately $24 \mathrm{~h}$ after initial plating, cells were treated with either $1 \%$ or $2 \%$ DMSO for $24 \mathrm{~h}$ in the maintenance medium. Representative brightfield images after DMSO treatment are shown in Figure 1. Consistent with previous reports for iPSCs maintained in a monolayer ${ }^{3}$, DMSO pretreatment resulted in a transient dose-dependent decrease in growth rate as compared to non-DMSO treated cells (Figure 1A). This decreased proliferation is associated with an increase in cell-to-cell contact, which is especially pronounced in the $2 \%$ DMSO treated cells displaying increased formation of more highly clustered cell colonies. In other cell types, DMSO-induced G1 arrest has been shown to be associated with increased expression of proteins involved in cell-cell interactions that support contact-inhibition induced growth arrest ${ }^{36}$. In iPSCs maintained as 3D cell spheres, the DMSO treatment similarly increased the number of cell spheres (Figure 1B). Furthermore, DMSO treatment also resulted in less variable 3D sphere sizes, which has been previously shown to be indicative of improved differentiation capacity of the cells ${ }^{37}$. Importantly, neither $1 \%$ or $2 \%$ DMSO resulted in cell toxicity, as measured by viability counts $(n=3 ; 2 D$ culture $\%$ live $=$ control: $80 \pm 1.3$; $1 \%$ DMSO: $82 \pm 3.7,2 \%: 81 \pm 2.7$; 3 D culture $\%$ live $=$ control: $81 \pm 4.3 ; 1 \%$ DMSO: $82 \pm 6.7,2 \%: 82 \pm 2.7)$. Overall, these results are consistent with the notion that DMSO treatment alters the cell cycle and growth patterns in cultured stem cells. These effects on growth inhibition are reversible when the DMSO is removed from the medium, as previously shown ${ }^{3}$.

\section{DMSO treatment improves the differentiation of ESCs to the primary germ layers}

HUES6 hESCs were seeded on coated plates for $24 \mathrm{~h}$ followed by treatment with $2 \%$ DMSO for $24 \mathrm{~h}$ in the maintenance medium. Cells were then differentiated into the three primary germ layers following the treatment paradigms shown in Figure $\mathbf{2 A}^{30,31,32}$. Differentiated cells were then fixed and immunologically stained for prototypic markers of each respective germ layer (SOX17 for endoderm, brachyury for mesoderm, and SOX1 for ectoderm). As shown in Figure 2B, $24 \mathrm{~h}$ of pretreatment with 2\% DMSO increased the proportion of cells expressing each respective germ layer marker. This is consistent with previous reports from our lab showing increased immunoreactivity, gene expression, as well as absolute number of differentiated cells towards all germ layers in stem cells treated with DMSO ${ }^{3,5}$. HUES6 is an hESC line with very low propensity for differentiation across all lineages ${ }^{1}$, yet the DMSO treatment substantially improves its capacity to differentiate across all germ layers.

\section{DMSO treatment improves the differentiation to progenitor cell types}

To investigate the effect of DMSO on differentiation to CNS progenitor cell types, human iPSCs were differentiated to either neural progenitor cells (NPCs) or oligodendrocyte progenitor cells (OPCs). To generate NPCs, cells were pretreated with $2 \%$ DMSO for $24 \mathrm{~h}$ in the maintenance medium followed by 12 days of directed differentiation ${ }^{33}$ (Figure 3A). As shown in Figure 3B, 2\% DMSO pretreatment increased the expression of the NPC marker PAX6 as compared to control. Using another previously validated protocol ${ }^{34}$ (Figure 3 C), iPSCs were differentiated for 12 days into OPCs. Similar to NPCs, OPCs derived from iPSCs pretreated with $2 \%$ DMSO for $24 \mathrm{~h}$ demonstrated an increase proportion of cells expressing OPC markers OLIG2 (Figure 3D).

\section{An initial DMSO treatment persists to enhance differentiation into mature cell types}

To investigate the effect of DMSO on latter stages of a differentiation protocol, HUES8 hESCs were pretreated for $24 \mathrm{~h}$ with $2 \%$ DMSO prior to differentiation to $\beta$ cells following a 20 day directed differentiation protocol described in Figure $4 a^{35}$. HUES 8 were used as they have been previously shown to have a higher propensity towards endodermal lineage ${ }^{1,38}$. At the definite endoderm stage, the differentiated cells express SOX17 and FOXA2, definitive endoderm (DE) specific markers. With further differentiation into the pancreatic progenitors $\left(\mathrm{PP}_{1}\right)$ stage, differentiated cells express PDX1 and FOXA2, markers characteristic of pancreatic progenitor cells. At these stages of pancreatic cell differentiation, the efficiencies of induction into DE and subsequently into $\mathrm{PP}_{1}$ were high for both control and DMSO-treated hESCs differentiated into each of these stages (Figure 4B, stages 1 and 3). Even though the HUES 8 cell line has been noted to have increased propensity to differentiate into the endodermal lineage, as differentiation is induced further into the more specialized cell types at the terminal stages the DMSO-treated hESCs are much more likely to produce mature pancreatic endocrine cells. The efficiencies of generating PDX1/ NKX6.1+ pancreatic progenitor cells, Neurogenin 3+ endocrine cells, and NKX6.1/C-peptide+ SC- $\beta$ cells were substantially higher in the DMSOtreated hESCs (Figure 4B, stages 4 and 5). These results are in line with the NPC and OPC differentiation showing that DMSO enhances the differentiation potential to progenitor cell types and also demonstrates that the effect of DMSO is persistent in generating more specialized cell types. This is consistent with prior work, where we have shown that the initial $24 \mathrm{~h}$ DMSO treatment increases differentiation into terminal cell types across germ layers, including into neuronal cells as well as beating cardiomyocytes ${ }^{31,39}$ in cell lines with high or poor propensities for differentiation ${ }^{3}$.

\section{Initial DMSO treatment improves hESC-derived cell function following in vivo transplantation}

Previously, we have demonstrated the effectiveness of DMSO treatment in enhancing the differentiation of hESCs into functional pancreatic progenitor cells that later show a marked improvement in insulin secretion in vivo ${ }^{3}$. Using previously published protocols $\mathrm{s}^{3,30,40}, \mathrm{HUES} \mathrm{hESCs}$ were treated with $1 \%$ DMSO for $24 \mathrm{~h}$, differentiated into pancreatic progenitor cells, and transplanted into immunodeficient SCID-Beige mice to assess functionality (e.g., insulin secretion in response to a glucose challenge or $\mathrm{KCl}$ stimulation) (Figure 5A). While the efficiencies of differentiation into FOXA2+ $(\sim 90 \%)$ and PDX1+ ( 75\%) pancreatic progenitors were comparable between control and DMSO-treated hESCs (Figure 5B) for the HUES8 hESC line, the cells differentiated from hESCs following a $24 \mathrm{~h} 1 \%$ DMSO treatment had improved responsiveness to glucose and $\mathrm{KCl}$ stimulation following in vivo transplantation. Improvements in functionality were evident within 2 weeks post-transplantation (Figure 5C) and persisted up to at least 16 weeks post-transplantation (Figure 5D). Taken together, these results suggest that DMSO pretreatment not only increases the differentiation efficiency to germ layers, progenitor cells, and more mature cell types, but also that it persists to enhance functionality of the differentiated cells in vivo. 


\begin{tabular}{|c|c|c|c|c|}
\hline Differentiated Cell Type & Starting Cell Type & $\%$ DMSO & $\begin{array}{l}\text { Length of DMSO } \\
\text { Treatment }\end{array}$ & $\begin{array}{l}\text { Length of DMSO } \\
\text { Treatment }\end{array}$ \\
\hline Hepatic cells & $\begin{array}{l}\text { ESC } \\
\text { Hepatoma cell line } \\
\text { ESC } \\
\text { ESC } \\
\text { Mesenchymal stem cells } \\
\text { iPSCs } \\
\text { ESC } \\
\text { ESC } \\
\text { Hepatoma cell line } \\
\text { ESC }\end{array}$ & $\begin{array}{l}1.0 \\
1.0 \\
1.0 \\
0.5 \\
0.1-2.0 \\
1.0 \\
1.0 \\
0.5 \\
1.0 \\
0.6\end{array}$ & $\begin{array}{l}8 \text { days } \\
\text { Several days } \\
7 \text { days } \\
10-14 \text { days } \\
7-21 \text { days } \\
7 \text { days } \\
4 \text { days } \\
5 \text { days } \\
2-21 \text { days } \\
\text { Throughout }\end{array}$ & \begin{tabular}{|l} 
Basma et al., 2008 \\
Kanebratt and Andersson, \\
2008 \\
Hay et al., 2009 \\
Duan et al., 2010 \\
Alizadeh et al., 2014 \\
Kondo et al., 2014 \\
Szkolnicka et al., 2014 \\
Czysz et al., 2015 \\
Nikolaou et al., 2016 \\
Vanhove et al., 2016
\end{tabular} \\
\hline Primary germ layers & $\begin{array}{l}\text { ESCs and iPSCs } \\
\text { hESC } \\
\text { hESC }\end{array}$ & $\begin{array}{l}0.1-2.0 \\
0.5 \\
0.1-2.0\end{array}$ & $\begin{array}{l}24 \text { hours } \\
24 \text { hours } \\
24 \text { hours }\end{array}$ & $\begin{array}{l}\text { Chetty et al., } 2013 \\
\text { Chetty et al., } 2015 \\
\text { Li et al., } 2018\end{array}$ \\
\hline Cardiac cells & $\begin{array}{l}\text { ESCs and iPSCs } \\
\text { P19 cells } \\
\text { ESCs and iPSCs } \\
\text { Fetal mesenchymal stem } \\
\text { cells }\end{array}$ & $\begin{array}{l}0.1-2.0 \\
1.0 \\
1.0-2.0 \\
0.8-1.0\end{array}$ & \begin{tabular}{|l}
24 hours \\
4 days \\
$24-30$ hours \\
24 hours
\end{tabular} & \begin{tabular}{|l} 
Chetty et al., 2013 \\
Choi et al., 2014 \\
van den Berg et al., 2016 \\
Deng et al., 2017
\end{tabular} \\
\hline Pancreatic cells & $\begin{array}{l}\text { ESCs and iPSCs } \\
\text { hESC }\end{array}$ & $\begin{array}{l}0.1-2.0 \\
0.5\end{array}$ & $\begin{array}{l}24 \text { hours } \\
24 \text { hours }\end{array}$ & \begin{tabular}{|l|} 
Chetty et al., 2013 \\
Chetty et al., 2015
\end{tabular} \\
\hline Smooth muscle cells & P19 cells & 1.0 & 4 days & Choi et al., 2014 \\
\hline Endothelial cells & P19 cells & 1.0 & 4 days & Choi et al., 2014 \\
\hline Enterocytes & iPSCs & $0-1.6$ & 4 days & Ogaki et al., 2015 \\
\hline Gut epithelium & iPSCs & $0-1.6$ & 4 days & Ogaki et al., 2015 \\
\hline Neural cells & Marmoset iPSC & $0.05-2.0$ & 24 hours & Qiu et al., 2015 \\
\hline Neutrophils & Leukemia cell line & 1.25 & $6-8$ days & $\begin{array}{l}\text { Teimourian and Moghanloo, } \\
2016\end{array}$ \\
\hline Skeletal Myotubes & iPSCs & 1.5 & 24 hours & Swartz et al., 2016 \\
\hline Cortical organoid & hiPSCs & 1.0 & 24 hours & Yoon et al., 2018 \\
\hline
\end{tabular}

Table 1: Summary of previously published work demonstrating the beneficial effects of DMSO treatment on differentiation.

\begin{tabular}{|c|c|c|c|c|}
\hline & S1 & S2 & S3 & S5 \\
\hline MCDB131 (L) & 1 & 1 & 1 & 1 \\
\hline Glucose (g) & 0.44 & 0.44 & 0.44 & 3.6 \\
\hline $\mathrm{NaHCO} 3(\mathrm{~g})$ & 2.46 & 1.23 & 1.23 & 1.754 \\
\hline FAF-BSA (g) & 20 & 20 & 20 & 20 \\
\hline ITS-X (mL) & 0.02 & 0.02 & 5 & 5 \\
\hline Glutamax (mL) & 10 & 10 & 10 & 10 \\
\hline Vitamin C (mg) & 44 & 44 & 44 & 44 \\
\hline Heparin (mg) & 0 & 0 & 0 & 10 \\
\hline $\mathrm{P} / \mathrm{S}(\mathrm{mL})$ & 10 & 10 & 10 & 10 \\
\hline
\end{tabular}

Table 2: Components of endocrine progenitor cell differentiation base medias. 

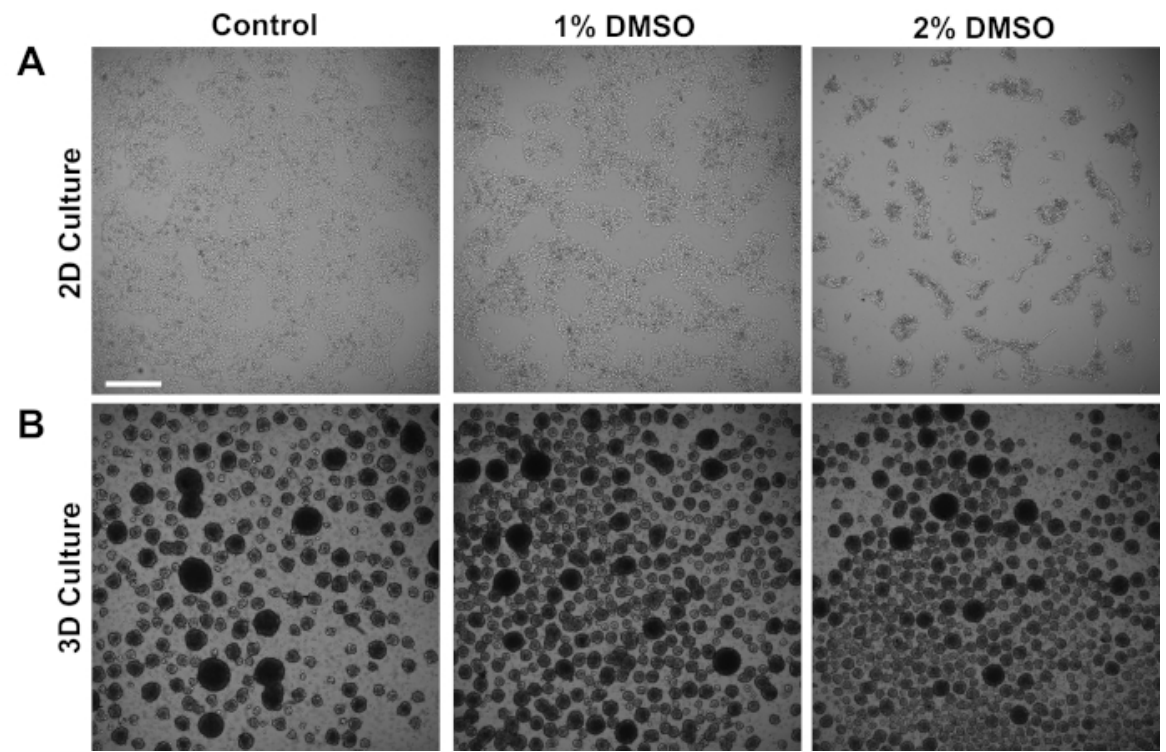

Figure 1: DMSO treatment alters the growth of hPSCs. (A) Representative brightfield images of hiPSCs plated in a monolayer after receiving no treatment (control) or treatment with $1 \%$ or $2 \%$ DMSO for $24 \mathrm{~h}$. DMSO promotes a transient dose-dependent growth inhibition of iPSCs. (B) Representative brightfield images of hiPSCs plated on low-attachment plates to allow 3D sphere formation after receiving no treatment (control) or treatment with $1 \%$ or $2 \%$ DMSO for $24 \mathrm{~h}$. DMSO treatment results in less variable 3D sphere formation compared to control. Scale bar $=500$ $\mu \mathrm{m}$. Please click here to view a larger version of this figure.

A

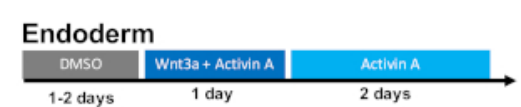

Mesoderm

\begin{tabular}{c|c|}
$\stackrel{\text { DMSO }}{\text { Wnt3a }+ \text { Activin } A}$ \\
\hline $1-2$ days & 1 day
\end{tabular}

\section{Ectoderm}

\begin{tabular}{cc}
$\underset{\text { DMSO }}{\text { Ectoderm }}$ & Nogsin +58431542 \\
\hline 1.2 days & 3 days
\end{tabular}

B
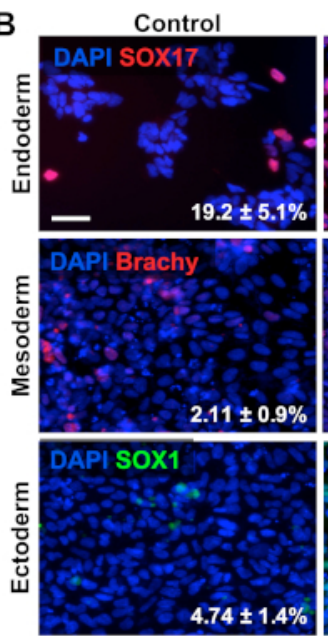

$2 \%$ DMSO
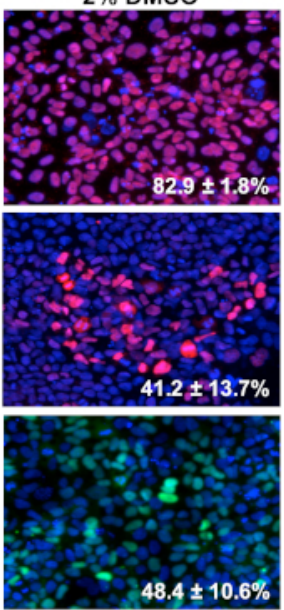

Figure 2: DMSO treatment improves differentiation of hPSCs to primary germ layers. (A) Schematic of differentiation protocols used to generate the three primary germ layers. (B) Representative images of differentiated HUES6 hESCs immunolabeled for SOX17 (endoderm), brachyury (mesoderm), and SOX1 (ectoderm). Pretreatment with $2 \%$ DMSO for $24 \mathrm{~h}$ increased the differentiation efficiency across all three germ layers. Percentages of cells differentiating into SOX17+ endodermal, Brachyury (Brachy)+ mesodermal, or SOX1+ ectodermal cells following directed differentiation into each germ layer of control and DMSO-treated hESCs are noted with SEM of three biological replicates. Unpaired ttest: endoderm $p=0.0003$; mesoderm $p=0.047$; ectoderm $p=0.015$. Scale bar $=50 \mu \mathrm{m}$. Please click here to view a larger version of this figure. 


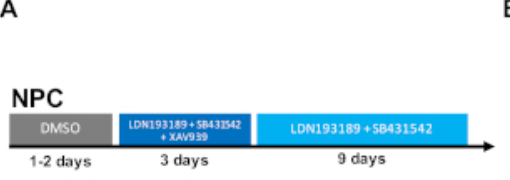

C

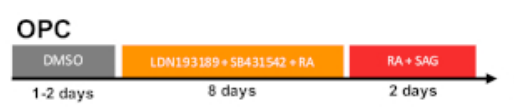

B
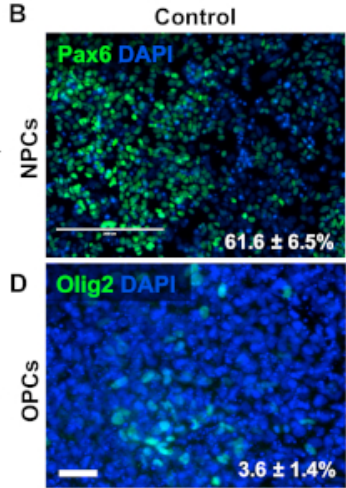

$2 \%$ DMSO
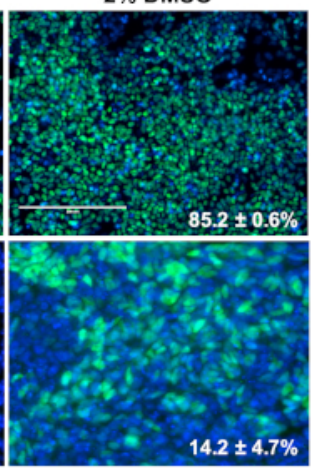

Figure 3: DMSO treatment improves differentiation to neural progenitor cell types. (A) Schematic of differentiation protocol used to generate neural progenitor cells (NPCs). (B) Representative images of human iPSCs differentiated into NPCs immunolabeled for Pax6. $24 \mathrm{~h}$ of pretreatment with $2 \%$ DMSO increased the number PAX6 positive cells. Percentages of cells differentiating into Pax6+ NPCs following directed differentiation of control and DMSO-treated human iPSCs are noted with SEM of three biological replicates. Unpaired t-test: $p=0.0225$. Scale bar $=200 \mu \mathrm{m}$. (C) Schematic of differentiation protocol used to generate oligodendrocyte progenitor cells (OPCs). (D) Representative images of human iPSCs differentiated into OPCs immunolabeled for OPC markers Olig2. $24 \mathrm{~h}$ of pretreatment with $2 \%$ DMSO increased the expression of both OPC markers compared to control. Percentages of cells differentiating into Olig2+ OPCs following directed differentiation of control and DMSO-treated human iPSCs are noted with SEM of four biological replicates. Unpaired t-test: $p=0.0466$. Scale bar $=50 \mu \mathrm{m}$. Please click here to view a larger version of this figure.

\section{A}

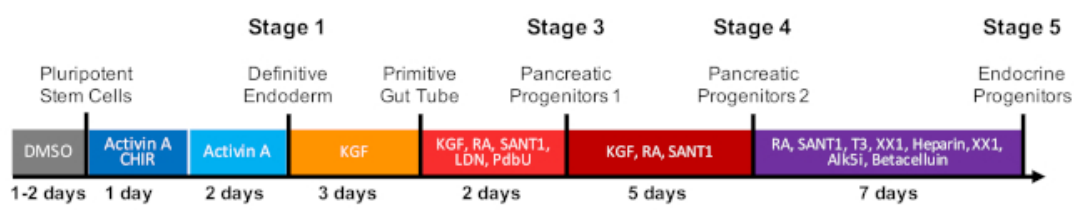

B

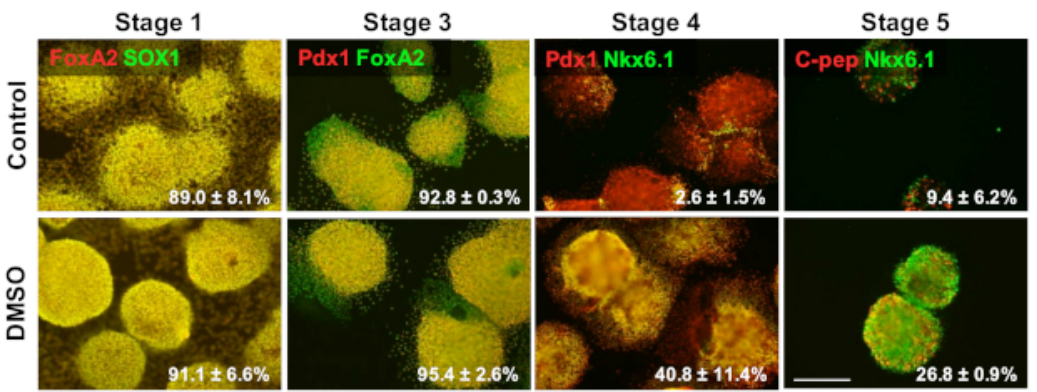

Figure 4: DMSO treatment enhances terminal differentiation potential of hPSCs. (A) Schematic of a $\sim 20$ day directed differentiation of HUES8 hESCs into terminally differentiated pancreatic endocrine cells. (B) Immunostaining for the indicated markers at each stage of differentiation following directed differentiation of untreated control cells and cells pretreated with $2 \%$ DMSO for $24 \mathrm{~h}$. The initial DMSO treatment persists to increase differentiation into terminal endocrine cell types at the latter stages of directed differentiation. Percentages of cells differentiating into the indicated markers at each stage of differentiation following directed differentiation of control and DMSO-treated hESCs are noted with SEM of two to four biological replicates. Scale bar $=200 \mu \mathrm{m}$. Please click here to view a larger version of this figure. 
A

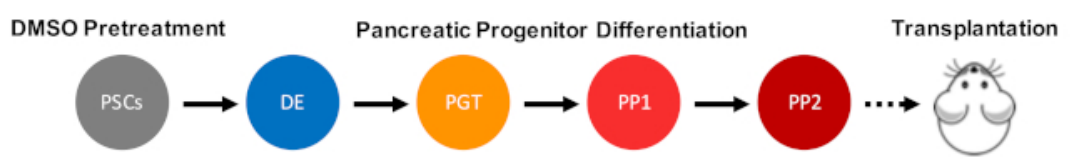

B

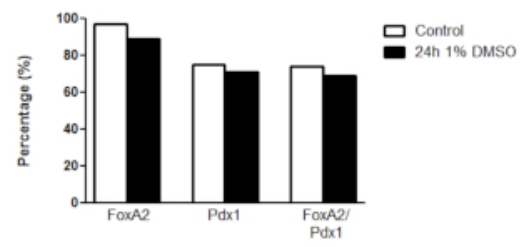

C

2 weeks post-transplantation

D 16 weeks post-transplantation
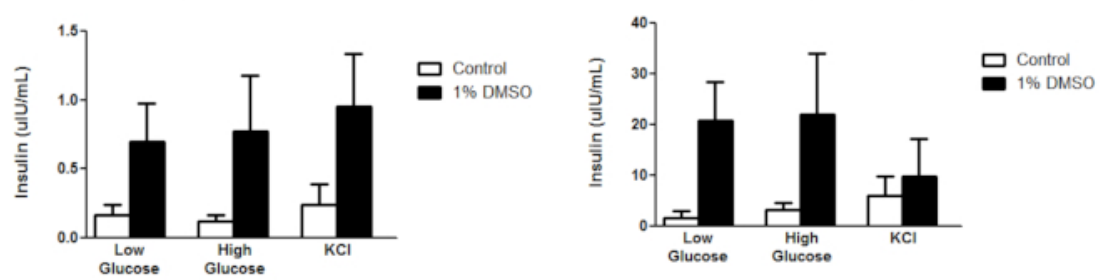

Figure 5: Initial DMSO treatment of hPSCs enhances glucose responsiveness following transplantation of pancreatic progenitor cells in vivo. (A) Schematic of directed differentiation ( 15 days) of HUES8 hESCs into pancreatic progenitor cells $\left(\mathrm{PP}_{2}\right)$ following no treatment (control) or a $24 \mathrm{~h} 1 \%$ DMSO treatment and subsequent transplantation (5 million cells) into immunodeficient SCID-Beige mice. (B) Percentage of cells differentiating into PDX1+ and FOXA2+ pancreatic progenitor cells following in vitro directed differentiation of control and DMSO-treated hESCs immediately before transplantation $(n=1)$. (C) Mean ELISA measurements of human insulin from the serum of mice following a low $(2.5 \mathrm{mM})$ or high $(15 \mathrm{mM})$ glucose challenge or potassium chloride $(\mathrm{KCl})$ stimulation at $(\mathbf{C}) 2$ weeks and $(\mathbf{D}) 16$ weeks post-transplantation of pancreatic progenitor cells differentiated from control and DMSO-treated hESCs (error bars $=\mathrm{SEM} ; \mathrm{n}=3$ at 2 weeks and 16 weeks for control; $\mathrm{n}=2$ at 2 weeks and 16 weeks for DMSO). Two-way ANOVA: $p=0.0051$ for control vs. DMSO at 2 weeks; $p=0.0116$ for control vs. DMSO at 16 weeks. The mice studied at the different time points are different. Results are adapted from Chetty et al. ${ }^{3}$. Please click here to view a larger version of this figure.

\section{Discussion}

In summary, this protocol describes a simple and inexpensive tool to enhance the differentiation capacity of pluripotent stem cells (PSCs) to all primary germ layers, various types of specialized progenitor cells, and even functional, mature cell types in in vitro and in vivo settings. Illustrated are specific differentiation protocols that have been effectively reproduced in our laboratory as well as others, but any differentiation protocol of choice can be used following the DMSO treatment. As shown in Table 1, a number of laboratories have also demonstrated an enhancement of PSC differentiation after transient DMSO treatment using different paradigms to generate various other terminal cell types. Furthermore, although the methods here describe the use of human PSCs, the DMSO pretreatment can be utilized across species and has been shown to be effective in mouse, rabbit, and primate PSCs.

Although higher doses of DMSO are known to be cytotoxic, the low doses used in this method (1\%-2\%) for a transient period result in minimal cell death. While overall cell numbers immediately after DMSO treatment may decrease due to DMSO promotion of cell cycle arrest in the G1 phase of the cell cycle, previous studies show that cells are able to reach the same level of confluency as control cultures after removal of $\mathrm{DMSO}^{3}$.

The percent and duration of DMSO pretreatment should be optimized per cell line. The treatment time should be adjusted with consideration for the cycling/doubling time of the cells. For example, mouse PSCs typically have much shorter cycling times of about $15 \mathrm{~h}$; thus, DMSO treatment for $15 \mathrm{~h}$ for these cells is sufficient. Some labs have also found the DMSO treatment to be beneficial when continued during the differentiation protocol or at lower concentrations (see Table 1). It should be noted that some PSC lines are more amendable to differentiation to specific lineages. For example, HUES6 cells have been shown to be less permissive to differentiation and thus had marked improvement with DMSO treatment (Figure 2). Alternatively, HUES8 cells used in Figure $\mathbf{4}$ and Figure $\mathbf{5}$ have been shown to have a higher propensity towards endodermal differentiation; thus, fewer differences were shown between control and DMSO for differentiation at the initial stages towards definitive endoderm. Nonetheless, the enhancement of DMSO pretreatment is observed in later stages of differentiation in this cell line (Figure 4B). The DMSO treatment is also versatile in that it is effective in both $2 \mathrm{D}$ and $3 \mathrm{D}$ cell cultures systems, it can be used with various types of coating material on cell culture plates, and it works in different types of maintenance medium that promote growth and expansion of hPSCs (e.g., mTeSR, E8, MEF conditioned media, etc).

More generally, these results suggest that the starting state of pluripotent stem cells has a strong influence on the propensity for initial differentiation as well as terminal differentiation into functional cell types. We have previously shown that the DMSO treatment functions through $\mathrm{Rb}$ in hPSCs ${ }^{3,5}$. Rb plays an important role in promoting terminal differentiation, cell survival, and the genetic stability of cells ${ }^{41,42,43,44}$, and it may therefore explain the persistent effects on cells differentiated from DMSO-treated hPSCs. Targeting these early modes of regulation may place hPSCs on a better trajectory for differentiation and ultimately improve their utility for regenerative medicine. 


\section{Disclosures}

The authors having nothing to disclose.

\section{Acknowledgments}

This work was supported by grants from the Stanford University School of Medicine and a Siebel Fellowship awarded to S. C.

\section{References}

1. Osafune, K. et al. Marked differences in differentiation propensity among human embryonic stem cell lines. Nature Biotechnology. 26 (3), 313-315, (2008)

2. Tabar, V., Studer, L. Pluripotent stem cells in regenerative medicine: challenges and recent progress. Nature Review Genetics. 15 (2), $82-92$, (2014).

3. Chetty, S. et al. A simple tool to improve pluripotent stem cell differentiation. Nature Methods. 10 (6), 553-556, (2013)

4. Conklin, J. F., Sage, J. Keeping an eye on retinoblastoma control of human embryonic stem cells. Journal of Cellular Biochemistry. 108 (5), 1023-1030, (2009).

5. $\mathrm{Li}$, J. et al. A transient DMSO treatment increases the differentiation potential of human pluripotent stem cells through the Rb family. PLoS One. 13 (12), e0208110, (2018).

6. Hartwell, L. H., Weinert, T. A. Checkpoints: controls that ensure the order of cell cycle events. Science. 246 (4930), 629-634 (1989).

7. Pardee, A. B. G1 events and regulation of cell proliferation. Science. 246 (4930), 603-608 (1989).

8. Orford, K. W., Scadden, D. T. Deconstructing stem cell self-renewal: genetic insights into cell-cycle regulation. Nature Review Genetics. 9 (2), 115-128, (2008).

9. Ying, Q. L. et al. The ground state of embryonic stem cell self-renewal. Nature. 453 (7194), 519-523, (2008).

10. Basma, H. et al. Differentiation and transplantation of human embryonic stem cell-derived hepatocytes. Gastroenterology. 136 (3), $990-999$, (2009).

11. Hay, D. C. et al. Efficient differentiation of hepatocytes from human embryonic stem cells exhibiting markers recapitulating liver development in vivo. Stem Cells. 26 (4), 894-902, (2008).

12. Duan, Y. et al. Differentiation and characterization of metabolically functioning hepatocytes from human embryonic stem cells. Stem Cells. 28 (4), 674-686, (2010).

13. Szkolnicka, D., Farnworth, S. L., Lucendo-Villarin, B., Hay, D. C. Deriving functional hepatocytes from pluripotent stem cells. Current Protocols in Stem Cell Biology. $301 \mathrm{G} 5$ 1-12, (2014).

14. Vanhove, J. et al. H3K27me3 Does Not Orchestrate the Expression of Lineage-Specific Markers in hESC-Derived Hepatocytes In Vitro. Stem Cell Reports. 7 (2), 192-206, (2016).

15. Kanebratt, K. P., Andersson, T. B. Evaluation of HepaRG cells as an in vitro model for human drug metabolism studies. Drug Metabolism \& Disposition. 36 (7), 1444-1452, (2008).

16. Nikolaou, N., Green, C. J., Gunn, P. J., Hodson, L., Tomlinson, J. W. Optimizing human hepatocyte models for metabolic phenotype and function: effects of treatment with dimethyl sulfoxide (DMSO). Physiological Reports. 4 (21), (2016).

17. Kondo, Y. et al. An efficient method for differentiation of human induced pluripotent stem cells into hepatocyte-like cells retaining drug metabolizing activity. Drug Metabolism Pharmacokinetics. 29 (3), 237-243 (2014).

18. Alizadeh, E. et al. The effect of dimethyl sulfoxide on hepatic differentiation of mesenchymal stem cells. Artificial Cells, Nanomedicine, and Biotechnology. 44 (1), 157-164, (2016).

19. Czysz, K., Minger, S., Thomas, N. DMSO efficiently down regulates pluripotency genes in human embryonic stem cells during definitive endoderm derivation and increases the proficiency of hepatic differentiation. PLoS One. 10 (2), e0117689, (2015).

20. Ogaki, S., Morooka, M., Otera, K., Kume, S. A cost-effective system for differentiation of intestinal epithelium from human induced pluripotent stem cells. Scientific Reports. 5 17297, (2015).

21. Choi, S. C. et al. Mixl1 and Flk1 Are Key Players of Wnt/TGF-beta Signaling During DMSO-Induced Mesodermal Specification in P19 cells. Journal of Cellular Physiology. 230 (8), 1807-1821, (2015).

22. Chetty, S. et al. A Src inhibitor regulates the cell cycle of human pluripotent stem cells and improves directed differentiation. Journal of Cell Biology. 210 (7), 1257-1268, (2015).

23. Qiu, Z. et al. Marmoset induced pluripotent stem cells: Robust neural differentiation following pretreatment with dimethyl sulfoxide. Stem Cell Research. 15 (1), 141-150, (2015).

24. Swartz, E. W. et al. A Novel Protocol for Directed Differentiation of C9orf72-Associated Human Induced Pluripotent Stem Cells Into Contractile Skeletal Myotubes. Stem Cells Translational Medicine. 5 (11), 1461-1472, (2016).

25. Teimourian, S., Moghanloo, E. Thwarting PTEN Expression by siRNA Augments HL-60 Cell Differentiation to Neutrophil-Like Cells by DMSO and ATRA. DNA Cell Biology. 35 (10), 591-598, (2016).

26. van den Berg, C. W., Elliott, D. A., Braam, S. R., Mummery, C. L., Davis, R. P. Differentiation of Human Pluripotent Stem Cells to Cardiomyocytes Under Defined Conditions. Methods in Molecular Biology. 1353, 163-180, (2016).

27. Deng, F. et al. Combination of retinoic acid, dimethyl sulfoxide and 5-azacytidine promotes cardiac differentiation of human fetal liver-derived mesenchymal stem cells. Cell Tissue Bank. 17 (1), 147-159, (2016).

28. Yoon, S. J. et al. Reliability of human cortical organoid generation. Nature Methods. 16 (1), 75-78, (2018).

29. Stratigopoulos, G., De Rosa, M. C., LeDuc, C. A., Leibel, R. L., Doege, C. A. DMSO increases efficiency of genome editing at two non-coding loci. PLoS One. 13 (6), e0198637, (2018).

30. Kroon, E. et al. Pancreatic endoderm derived from human embryonic stem cells generates glucose-responsive insulin-secreting cells in vivo. Nature Biotechnology. 26 (4), 443-452, (2008). 
31. Zhang, P. et al. Short-term BMP-4 treatment initiates mesoderm induction in human embryonic stem cells. Blood. 111 (4), 1933-1941, (2008).

32. Chambers, S. M. et al. Highly efficient neural conversion of human ES and iPS cells by dual inhibition of SMAD signaling. Nature Biotechnology. 27 (3), 275-280, (2009).

33. Tchieu, J. et al. A Modular Platform for Differentiation of Human PSCs into All Major Ectodermal Lineages. Cell Stem Cell. 21 (3), $399-410$ e397, (2017).

34. Douvaras, P., Fossati, V. Generation and isolation of oligodendrocyte progenitor cells from human pluripotent stem cells. Nature Protocols. (8), 1143-1154, (2015).

35. Pagliuca, F. W. et al. Generation of functional human pancreatic beta cells in vitro. Cell. 159 (2), 428-439, (2014).

36. Fiore, M., Degrassi, F. Dimethyl sulfoxide restores contact inhibition-induced growth arrest and inhibits cell density-dependent apoptosis in hamster cells. Experimental Cell Research. 251 (1), 102-110, (1999).

37. Dang, S. M., Kyba, M., Perlingeiro, R., Daley, G. Q., Zandstra, P. W. Efficiency of embryoid body formation and hematopoietic development from embryonic stem cells in different culture systems. Biotechnology and Bioengineering. 78 (4), $442-453$ (2002).

38. Bock, C. et al. Reference Maps of human ES and iPS cell variation enable high-throughput characterization of pluripotent cell lines. Cell. 144 (3), 439-452, (2011).

39. Lian, X. et al. Robust cardiomyocyte differentiation from human pluripotent stem cells via temporal modulation of canonical Wnt signaling. Proceedings of the National Academy of Sciences of the United States of America. 109 (27), E1848-1857, (2012).

40. D'Amour, K. A. et al. Production of pancreatic hormone-expressing endocrine cells from human embryonic stem cells. Nature Biotechnology 24 (11), 1392-1401, (2006).

41. Jacks, T. et al. Effects of an Rb mutation in the mouse. Nature. 359 (6393), 295-300, (1992)

42. Nguyen, D. X., Baglia, L. A., Huang, S. M., Baker, C. M., McCance, D. J. Acetylation regulates the differentiation-specific functions of the retinoblastoma protein. The EMBO Journal. 23 (7), 1609-1618, (2004).

43. Slack, R. S. et al. Cells differentiating into neuroectoderm undergo apoptosis in the absence of functional retinoblastoma family proteins. Journal of Cell Biology. 129 (3), 779-788 (1995).

44. Gu, W. et al. Interaction of myogenic factors and the retinoblastoma protein mediates muscle cell commitment and differentiation. Cell. 72 (3), 309-324 (1993). 